\title{
Smart Safety Kit (Android App and Device) - Fire Safety
}

\author{
Rohan Mandhanya \\ Student \\ Indore, MP \\ India
}

\author{
Pragya Singhal \\ Student \\ Indore, MP \\ India
}

\begin{abstract}
In India there is only $2 \%$ fire safety. On an average, in India, every year, about 25,000 persons die due to fires and related causes. In the year 2007-2008 about $45 \%$ of the claims are due to fire losses. According to another estimate about Rs. 1000 crores are lost every year due to fire. Fire losses are reported both in industrial and non-industrial premises like hospitals, commercial complexes, educational institutions, assembly halls, hotels, residential buildings, etc. Probably many of these deaths and economic losses could have been prevented, had we taken enough fire protection measures. So the main intent of this project is to reduce such losses beforehand by preventing the fire by incorporating an android application(used by majority of people) with a device(cheaper then the existing ones) consisting of arduino board, smoke sensor, heat sensor, LPG leakage sensor and GSM module.
\end{abstract}

\section{General Terms}

Safety device, Fire safety

\section{Keywords}

Arduino, IR-Module, Gas Module, LM-35 Module, GSM, Android

\section{INTRODUCTION}

In today's era we want everything to be smart that is why we are designing each and every design with smart features. So, what if safety can become smart too. Fire safety was invented millions of years ago when mankind discovered fire. We invented fire safety to prevent us from getting hurt. We want solutions to our day to day problems on one click and it is being possible by many ways. Fire safety never got smart before this as we never thought to stop the fire before it became a hazard. This paper proposes a new smart safety which will prevent us from future hazards. Safety is one of the important aspects for everyone. This device is designed with the intention of increasing fire safety. As fire hazards in world has been increased after technology has evolved, so why not use technology only to prevent hazards that can happen in future.

\section{PURPOSE}

The main purpose of this project is to decrease fir safety beforehand by knowing in advance that what can lead to fire. The device is also cheap as compared to existing fire safety devices so it can be affordable by middle class people also. Also, nowadays each and every person owns an android phone so it would not be problem as it can be used by anyone.

\section{BACKGROUND}

\subsection{Model: ARD132D2P}

The Arduino Uno Rev3 is a microcontroller board based on the ATmega328 (datasheet) on which all the other devices are being connected. It has 6 analog inputs, 14 digital input/output pins, a USB connection, a $16 \mathrm{MHz}$ crystal oscillator, a power jack, a reset button and an ICSP header. It can be simply connected with an USB cable to the computer or power it with a AC-to-DC adapter or battery to get started. Instead of using FTDI USB to serial driver chip, it uses the Atmega8U2 programmed as a USB-to-serial converter.

\subsection{LM-35 Module}

LM35 is being used as the smoke sensor in the device. Its output is proportional to the temperature (in ${ }^{\circ} \mathrm{C}$ ). Its circuitry is sealed so, it is not subjected to oxidation and other processes. Low self heating is being possessed by it and does not cause more than $0.1{ }^{\circ} \mathrm{C}$ temperature rise in still air. The range from $55^{\circ} \mathrm{C}$ to $150^{\circ} \mathrm{C}$ is its operating temperature range. Its scale factor is $0.01 \mathrm{~V} /{ }^{\circ} \mathrm{C}$.

\subsection{IR-Module}

The Infrared temperature sensor is being used as heat sensor and is a non-contact temperature sensor. A series of 116 elements of thermocouple are composed in it on a floating micro-membrane. This black surface is a good absorber of incident thermal infrared radiation. Output of this sensor is an analog voltage $(0 \sim 1.1 \mathrm{~V})$ according to target temperature.

\subsection{Gas Module}

LPG Gas Sensor Module is specially designed to detect LPG leak at a place whether it is a home or a car. This sensor include two pots in which one is used for trigger level setting and second one is used to set the sensitivity of the sensor. It also determines whether the preset LPG gas level have been reached or exceeded. The module uses MQ-6 sensor to sense LPG leak. To detect gas concentrations anywhere from 200 to 10000 ppm, MQ-6 is used.

\subsection{GSM Module}

It is used to send sms and make and receive calls. SIM300 is used by it for all its operations. It has standard RS232 interface which is used to easily interface the modem to micro controllers and computers. The modem consists of all the external circuitry required to start experimenting with the SIM300 module.

\subsection{Android Studio}

Android Studio is the officialintegrated development environment (IDE) for Android platform development. It is freely available under the Apache License 2.0. Its early access preview stage started in May 2013 as version 0.1 and then beta stage as version 0,8 which released in June 2014. In December 2014, the first stable build was released, starting from version 1.0. It is available for download on Windows, Mac OS X and Linux, and replaced Eclipse Android Development Tools (ADT) as Google's primary IDE for native Android application development.

\subsection{Arduino IDE}

The Arduino project provides the Arduino IDE, which is written in Java. It also supports the languages $\mathrm{C}$ and $\mathrm{C}++$ using special rules to organize code.. A typical Arduino $\mathrm{C} / \mathrm{C}++$ sketch consist of two functions that 
are compiled and linked with a program stub main() into an executable cyclic executive program:

1. $\operatorname{setup():~a~function~that~runs~once~at~the~start~of~a~}$ program and that can initialize settings.

2. $\operatorname{loop}()$ : a function called repeatedly until the board powers off.

\section{DESIGN AND IMPLEMENTATION}

The fire safety device is made up of arduino, the three sensors and gsm module. It can be installed at any place where there is more chances of fire explosion. Firstly, the owner of the device has to install the android application and register his details. User has to enter his phone number as well as his neighbors' phone number. If there is something that can lead to the fire and the device senses it then it will send an alert message to its owner. If owner does not reply within 5 minutes the the same alert message is sent to registered neighbors. If neighbors also do not respond within 5 minutes then device makes an automatic call to the fire brigade. In this way fire can be prevented and stopped.

\subsection{Android Code For Sms Receiver}

package com.example.money.agnikai;

import android.content.BroadcastReceiver;

import android.content.ContentResolver;

import android.content.Context;

import android.content.Intent;

import android.database.Cursor;

import android.net.Uri;

import android.os.Bundle;

import android.telephony.SmsMessage;

import java.net.URI;

public class SmsReciever extends BroadcastReceiver \{

String PhoneNumber="+91 9165 901561";

@Override

public void onReceive(Context context, Intent intent) \{

// get the sms message passed in

Bundle bundle=intent.getExtras();

SmsMessage[] msgs=null;

String str="";

if(bundle!=null)

\{

//-retrieve the Sms Recieved

Object[] pdus=(Object[])bundle.get("pdus");

msgs=new SmsMessage[pdus.length];

for(int $\mathrm{i}=0 ; \mathrm{i}<$ msgs.length; $i++)$

\{

$\operatorname{msgs}[\mathrm{i}]=$ SmsMessage.createFromPdu((byte[])pdus[i]);

String phNum=msgs[i].getOriginatingAddress(); if (PhoneNumber.equals(phNum))

\{

Uri uri=Uri.parse("content://sms/inbox");

ContentResolver

contentResolver=context.getContentResolver();

String where $=$ "address: $="+$ phNum;

Cursor cursor=contentResolver.query(uri,new String[]\{"_id","thread_id" \},where,null,null);

while (cursor.moveToNext())

\{

long thread_id=cursor.getLong $(1)$;

where ="thread_id"+thread_id;

Uri thread=Uri.parse("content://sms/inbox");

context.getContentResolver().delete(thread,where,null);

\}

Intent

$\mathrm{I}=$ new

Intent(context,ProfileActivity.class);

I.setFlags(Intent.FLAG_ACTIVITY_NEW_TASK);

I.putExtra("msg",str);

context.startActivity(I);

\}

\}

\}

\}

\}

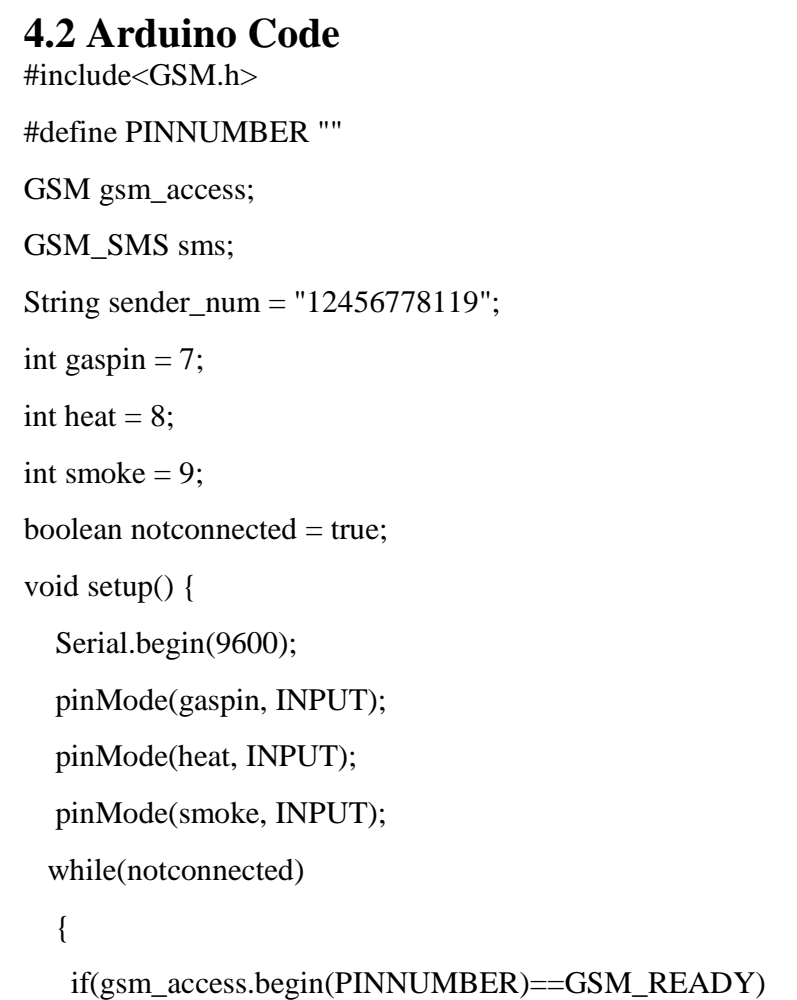




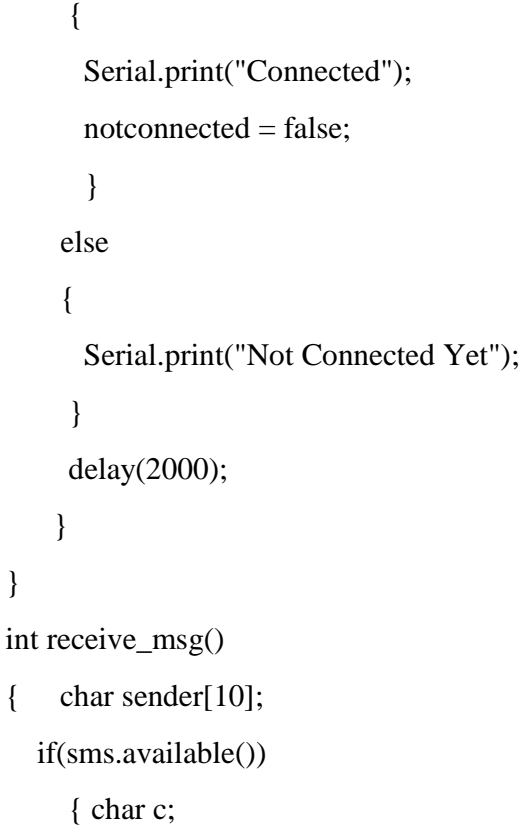

sms.beginSMS(mob_num);

sms.print(msg);

sms.endSMS();

delay(500000);//5 min delay

int $\mathrm{n}=$ receive_msg;

if $(\mathrm{n}==0)$

\{ char s[] ="999999999";

char $\mathrm{p}[]=$ "777777777";

sms.beginSMS(s);

sms.print(msg);

sms.endSMS();

sms.beginSMS(s);

sms.print(msg);

sms.endSMS();

\}

\}

\subsection{Android Application Working}

1. The first figure shows the splash screen. This is the screen which will be seen as soon as the application is being opened.

2. The next figure shows the registration screen. Here user has to register all his details including his phone number, neighbors' contacts and his address.

3. The next figure is the login form where user has to login into his id using username and password.

4. The next figure is the home page.

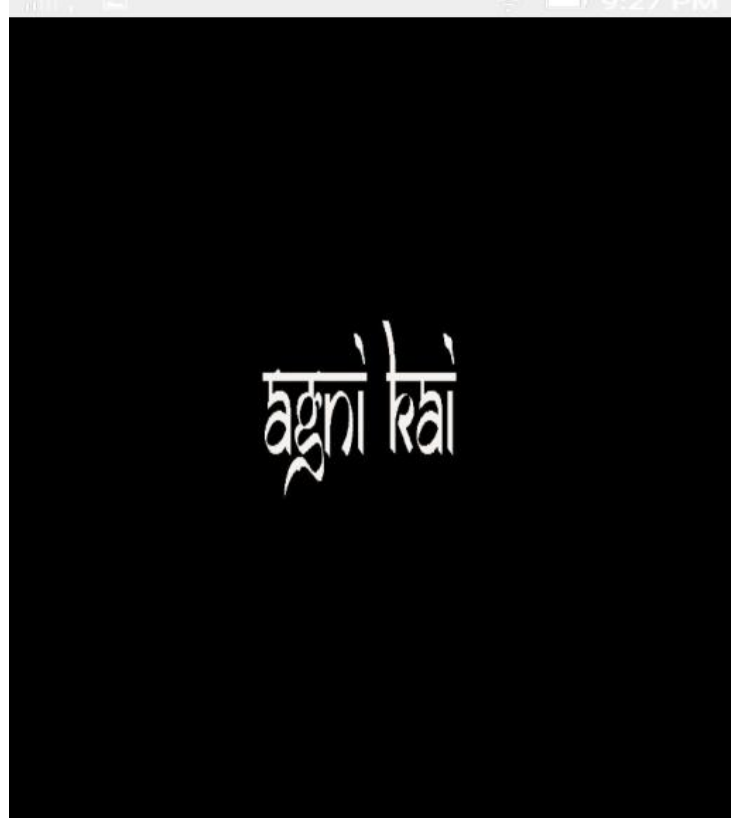

Figure 1: Splash Screen 


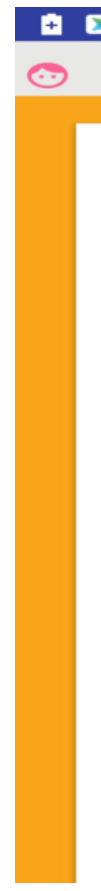

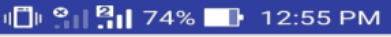

\section{Sign Up}

Username

\section{Add Neighbour's Contact \\ Address

Sign Up

Already a Member? Sign In!

Figure 2: Registration Form

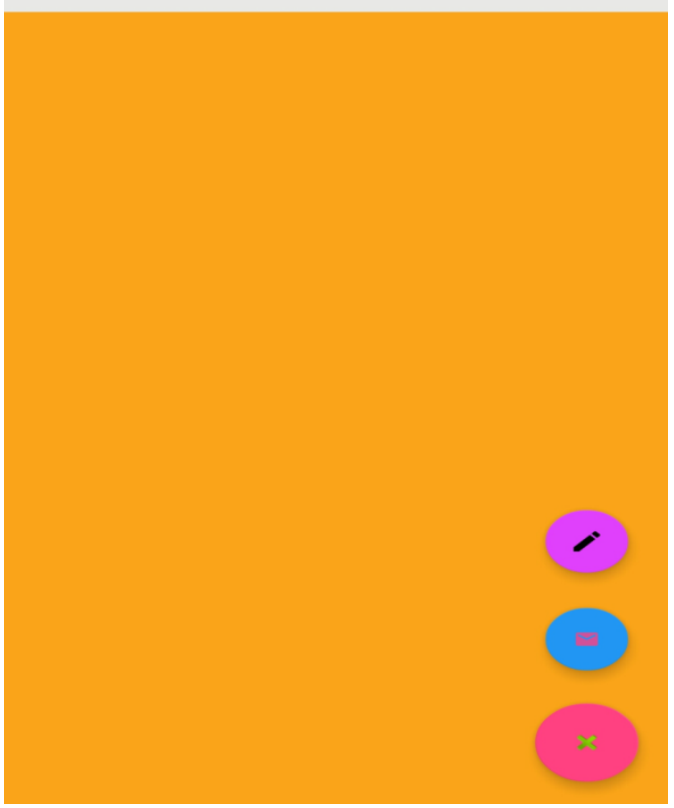

Figure 4: Home Page

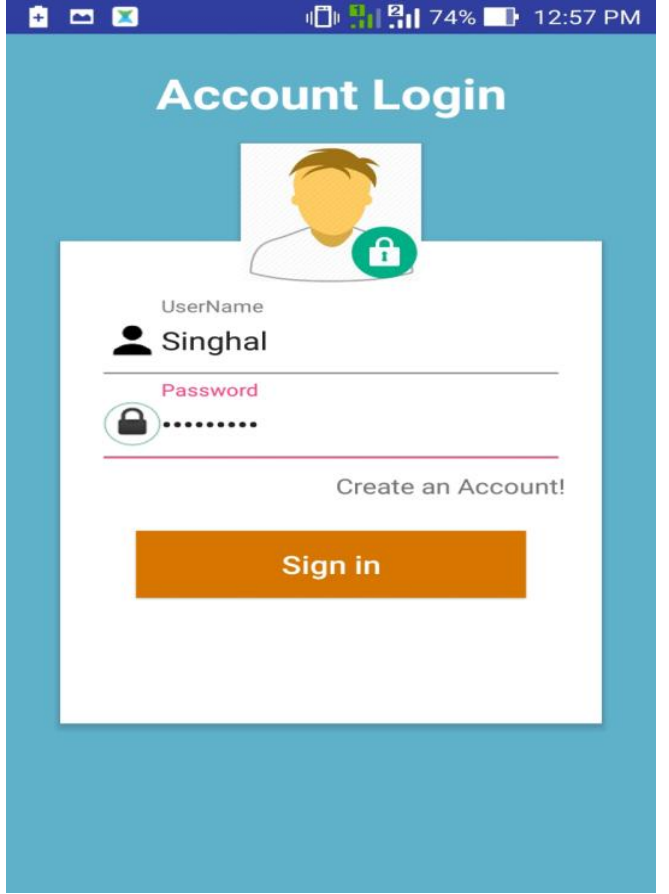

Figure 3: Login Form

\subsection{Working Of Device}

The code is burnt on the arduino board from the Arduino IDE. This code is written in embedded C. This code consists of the instructions like to whom and when to send alert message and how much tym it has to wait for the next step. GSM module is provided with the sim which is used for sending the alert.

1. Device senses anything wrong with the help of the three sensors.

2. It sends message to the user. User has to respond to message i.e., stop the cause that made device to send alert within 5 minutes.

3. If not responded within 5 minutes it sends alert to the registered neighbors. Neighbors also have to respond within 5 minutes.

4. 4. If neighbors also do not respond within 5 minutes then it makes an automatic call to fire brigade.

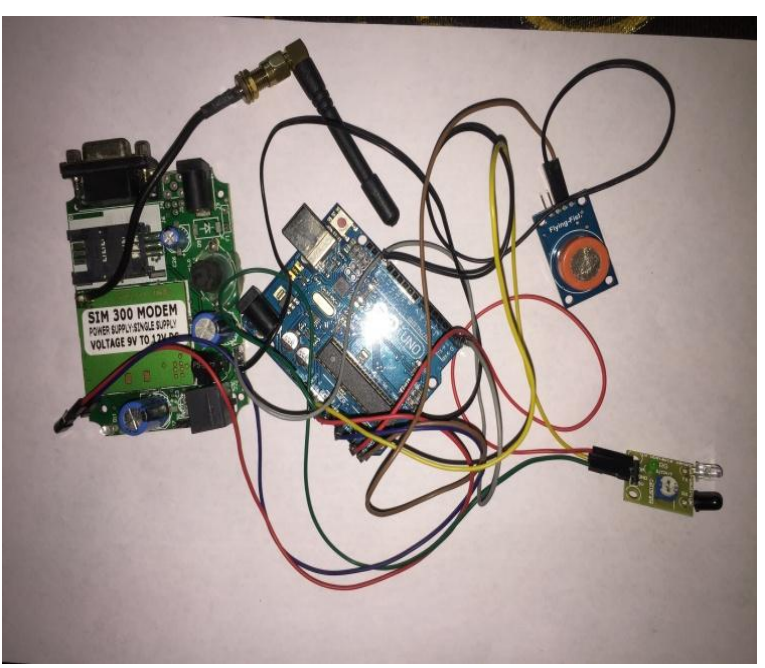

Fig 5: Arduino Device 


\section{FUTURE ENHANCEMENT}

The device can be further enhanced to increase its efficiency and proficiency. This can be done in various ways. Like, Bluetooth can be used for saving data and sending alert within a particular range. Furthermore, the three sensors can be installed at different places that can have fire due to different reasons. So, sensor for a particular purpose can be placed at that place. These devices can be connected together via a hub or a wifi. We can also increas other kinds of safety in this device by increasing other sensors for each safety.

\section{REFERENCES}

[1] http://www.arduino.cc/

[2] http://www.tutorialspoint.com/android/

[3] http://www.mybringback.com/series/androidintermediate/

[4] http://www.imo.org/en/OurWork/Safety/FireProtection/P ages/History-of-fire-protection-requirements.aspx

[5] https://developer.android.com/index.html

[6] http://www.sdmmag.com/articles/84060-conventionaland-addressable-wisdom

[7] http://php.net/manual/en/function.mysql-create-db.php

[8] http://tutorialspoint.com/php/create_mysql_database_usi ng_php

[9] http:// www.siteground.com/tutorials/php-mysql.htm

[10] https://en.wikipedia.org/wiki/Fire_alarm_system

[11] https://www.sitepoint.com/getting-started-mysql/

[12] http://www.developer.com/ws/android/understandingthe-android-platform-architecture.html

[13] https://www.infoq.com/articles/latest-mobile-appdevelopment-trends

[14] http://www.inmotionhosting.com/support/edu/websitedesign/using-php-and-mysql/grab-all-comments-fromdatabase
[15] Meier, Reto, “Android 4 Application Development”, $2^{\text {nd }}$ Edition, Indiana: John Wiley and Sns, Inc. August 2012.

[16] Raynaldo, Camilus, "The Android Programming Painless", New York: US Corporate and Government Sales, May 2012.

[17] Schwarz, Ronan, "The Android Developer's Cookbook", 2md Edition, New Jersey: Government Sales, June 2013.

[18] Greenspan, Jay. "MYSQL/PHP Database Applications" Chicago: M \& T Books. June 2013.

[19] Hammerberg, Thomas. "Conventional and Addressable Wisdom." SDM. $\quad$ May 1 2007.AxisCommunications.Web.8 MAY 2016 <http://www.sdmmag.com/articles/84060-conventionaland-addressable-wisdom>

[20] John, Rex. "Android Studio vs Eclipse: What you need to know." Airpair. December 152015. $<$ https://www.airpair.com/android/android-studio-vseclipse>

[21] Kanjilal, Joydip. "Understanding the Android application platform”. Quinstreet. March 42016 <http://www.developer.com/ws/android/understandingthe-android-platform-architecture.html $>$

[22] Markle, Brad. "How to use PHP to connect and retrieve data from MYSQL", SupportCenter. March 142014 http://www.inmotionhosting.com/support/edu/websitedesign/using-php-and-mysq1/grab-all-comments-fromdatabase

[23] Stanfield, Katie. "A Glimpse of Latest Mobile App Development Trends", C4Media Inc. Sep 22015 $<$ https://www.infoq.com/articles/latest-mobile-appdevelopment-trends>

[24] Yank, Kevin. "Build your own database driven application”, Sitepoint Pty.Ltd. July 172009 <https://www.sitepoint.com/getting-started-mysql/> 